\title{
Measurement of hypoxanthine incorporation in purified suspensions of Mycobacterium leprae: a suitable method to screen for anti-leprosy agents in vitro
}

\author{
P. R. WHEELER
}

Department of Biochemistry, University of Hull, Hull, HU6 7RX

\begin{abstract}
Summary. The rate of incorporation of hypoxanthine was measured in suspensions of Mycobacterium leprae, with and without added anti-leprosy agents. Dapsone, clofazamine and brodimoprim, as well as other benzylpyrimidines, inhibited hypoxanthine incorporation, and their minimum inhibitory concentrations for incorporation with intact $M$. leprae were near the minimum inhibitory concentrations at which the agents have antibacterial effects. At sub-inhibitory concentrations for hypoxanthine incorporation, some combinations of benzylpyrimidines and dapsone were inhibitory, suggesting that synergic effects of anti-leprosy agents might also be detected by the inhibition of hypoxanthine incorporation. Thus, demonstration of inhibition of hypoxanthine incorporation in $M$. leprae could be a rapid method for screening anti-leprosy agents and especially for preliminary testing of new, potential anti-leprosy agents. The rate of hypoxanthine incorporation was generally lower in suspensions of $M$. leprae with lower viability, but it was not proportional to viability so the technique would not be suitable for accurate determination of viability.
\end{abstract}

\section{Introduction}

Multi-drug therapy, usually with three antileprosy drugs, is now recommended for the treatment of leprosy (World Health Organization, 1985). However, there are problems with all the drugs in use. Drug resistance is well known with dapsone and has been reported recently with clofazamine (Warndorff-van Diepen, 1982) and rifampicin (Guelpa-Lauras et al., 1984). Also, during treatment with thioamides in combination with other antileprosy agents, serious toxic effects were observed in up to $15 \%$ of patients (Cartel et al., 1983; Pattyn et al., 1984). Clearly, there is an urgent need for new chemotherapeutic agents active against leprosy bacilli.

A major difficulty in testing potential anti-leprosy agents is the absence of a rapid, reliable method for drug screening. $M$. leprae can be grown reliably in the foot-pads of mice (Shepard, 1960; Colston et al., 1978) but it takes 6-12 months to assess the growth of the bacteria. Several alternatives to the mouse foot-pad have been suggested for screening anti-leprosy drugs and for detecting drug-resistant $M$. leprae. These include observations of the effects of live $M$. leprae on cholesterol metabolism (Nair and Mahadevan, 1984) and $\mathrm{F}_{\mathrm{c}}$-receptors of macrophages infected with leprosy bacilli (Mankar et al.,

Received 12 May 1986; revised version accepted 12 Dec 1986.
1984), and fluorescence of $M$. leprae organisms incubated with fluorescein diacetate (Kvach $e t$ al., 1984; Mankar et al., 1984). Other studies have used radio-isotopically labelled substrates to investigate the incorporation by $M$. leprae of dihydroxyphenylalanine (DOPA) (Ambrose et al., 1978), thymidine (Nath et al., 1982; Mittal et al., 1983), and hypoxanthine (Khanolkar and Wheeler, 1983). All of these effects and activities were inhibited by anti-leprosy agents when tested against intact $M$. leprae.

In this paper, hypoxanthine incorporation in $M$. leprae is examined in detail to ascertain whether it is (a) suitable for estimating the viability of suspensions of $M$. leprae by killing the bacteria in ways which would be expected to leave enzymes or even whole metabolic pathways active for some time and (b) suitable for screening anti-leprosy drugs. Anti-leprosy agents were tested alone, and in combination, to search for possible synergic effects.

\section{Materials and methods}

\section{Anti-leprosy chemotherapeutic agents}

Dapsone (4,4-diaminodiphenylsulphone) (Sigma) $2 \mathrm{mg} / \mathrm{ml}$ in $1 \mathrm{M} \mathrm{HCl}$ was diluted in distilled water. The benzylpyrimidines, SC-SE 60 and $\mathrm{Li} 014$, were gifts from Professor J. K. Seydel, Forschunginstitut Borstel, Par- 
kallee 1-40, 2061 Borstel, West Germany, and brodimoprim was a gift from both Professor J. K. Seydel and Dr P. Jenner, National Institute for Medical Research, Mill Hill, London NW7 1AA. Clofazamine was a gift from Dr S. O'Sullivan, Medical Research Council of Ireland, Dublin. Except for dapsone, agents were dissolved in dimethylsulphoxide (Analar) at 100-500 times the concentration needed in incubations: dimethylsulphoxide $1 \% \mathrm{v} / \mathrm{v}$ itself did not affect hypoxanthine incorporation in $M$. leprae.

\section{Suspensions of $M$. leprae}

$M$. leprae was isolated from armadillo spleen or liver as described previously (Wheeler, 1983). Briefly, tissues were homogenised in 'homogenisation medium' [0.2 Mtris (hydroxymethylaminomethane) base in $14 \mathrm{~mm} \mathrm{NaCl}$ with $1 \mathrm{mM} \mathrm{MgSO}_{4}$ ]. Homogenisation medium was used at the rate of $4 \mathrm{ml} / \mathrm{g}$ (wet weight) of infected tissue, resulting in a homogenate at $p \mathrm{H} \mathrm{8.7.} \mathrm{Bacteria} \mathrm{were}$ collected as a pellet by centrifugation at $8000 \mathrm{~g}$ for $10 \mathrm{~min}$. The pellet was washed (all washings were done by resuspension and centrifugation) once in buffer [ $30 \mathrm{mM}$ HEPES $\left(N\right.$-2-hydroxyethylpiperazine- $N^{1}$-2-ethanesulphonic acid) adjusted to $p \mathrm{H} \mathrm{7.2}$ with $\mathrm{NaOH}$, $136 \mathrm{mM} \mathrm{NaCl}, 1 \mathrm{mM} \mathrm{MgSO}_{4}$ and Tween $800.1 \% \mathrm{w} / \mathrm{v}$ ], and treated with DNAase I(Sigma) 4 units $/ \mathrm{ml}$ in Tween$800.1 \% \mathrm{w} / \mathrm{v}$ with $3 \mathrm{mM}$ HEPES and $1 \mathrm{~mm} \mathrm{MgSO} 4$, $p \mathrm{H} \mathrm{7.2,} \mathrm{used} \mathrm{at} \mathrm{rate} \mathrm{of} 4 \mathrm{ml} / \mathrm{g}$ (wet weight) original tissue, for $1 \mathrm{~h}$ at $20^{\circ} \mathrm{C}$. The suspension was filtered through a sieve ( $0.5 \mathrm{~mm}$ stainless steel mesh) to remove large pieces of debris, the pellet was collected $(8000 \mathrm{~g}, 10 \mathrm{~min})$ and the bacteria were resuspended in Tween $800.1 \% \mathrm{w} / \mathrm{v}$ and separated from tissue debris in a Percoll (Pharmacia, S75182 Uppsala, Sweden) $30 \%$ v/v gradient. The bacteria were then washed three times in Tween $800.1 \% \mathrm{w} / \mathrm{v}$ in 5 mM MES (2-[ $N$-morpholino] ethanesulphonic acid) adjusted to $p \mathrm{H} 6.8$ with $6 \mathrm{M} \mathrm{NaOH}$ (buffered Tween 80) and resuspended in buffered Tween 80 at three times the density required in incubations. All manipulations were done at $4^{\circ} \mathrm{C}$ unless otherwise stated. Further details about the isolation of $M$. leprae from infected tissues can be obtained from the report to the WHO (World Health Organization,1980).

\section{Suspensions of $M$. microti}

M. microti strain OV 254 (obtained from the National Institute for Medical Research, London NW7 1AA) $(3 \times$ $10^{9}$ organisms) were inoculated into $250 \mathrm{ml}$ flasks each containing $100 \mathrm{ml}$ of modified Dubos Medium $(p \mathrm{H} 7)$. They were grown statically at $37^{\circ} \mathrm{C}$ for 14 days by which time $c .3 \times 10^{11}$ organisms were present in each flask. Organisms were centrifuged, washed twice with buffered Tween 80 and resuspended in buffered Tween 80 at three times the density required in incubations.

\section{Incubation with radio-labelled substrates and anti- leprosy agents}

For hypoxanthine incorporation studies bacteria $\left(10^{9}-\right.$ $10^{10}$ organisms) were incubated at $34^{\circ} \mathrm{C}$ for $24 \mathrm{~h}$ in
$50 \mathrm{~mm}$ HEPES with $5 \mathrm{~mm} \mathrm{NaCl}, 1 \mathrm{mM} \mathrm{MgSO}_{4}$, $0.2 \mathrm{mM} \mathrm{NaH} \mathrm{PO}_{4}, 17 \mathrm{~mm}$ asparagine and $55 \mathrm{~mm}$ glucose; the $p \mathrm{H}$ was adjusted to 7.0 with $6 \mathrm{M} \mathrm{KOH}$ and $10 \mu \mathrm{M}$ uracil, $10 \mu \mathrm{M}$ thymidine and $10 \mu \mathrm{M}$ cytosine and penicillin $50 \mathrm{u} / \mathrm{ml}$ were added (Khanolkar and Wheeler, 1983) followed by $1 \mu \mathrm{Ci}\left[\mathrm{G}-{ }^{3} \mathrm{H}\right]$ hypoxanthine (Amersham; 2.8 $\mathrm{Ci} / \mathrm{mmol}$ ) in a final volume of $300 \mu \mathrm{l}$. For ${ }^{14} \mathrm{CO}_{2}$ evolution studies bacteria were incubated at $34^{\circ} \mathrm{C}$ for $20 \mathrm{~h}$ in $50 \mathrm{~mm}$ HEPES with $1 \mathrm{~mm} \mathrm{MgSO}, 5 \mathrm{mM} \mathrm{K}_{2} \mathrm{HPO}_{4}$ and penicillin $50 \mathrm{U} / \mathrm{ml}$; the $p \mathrm{H}$ was adjusted to 7.0 with $6 \mathrm{M}$ $\mathrm{KOH}$ (Wheeler, 1983) and $1 \mu \mathrm{Ci}\left(\mathrm{U}^{-14} \mathrm{C}\right)$ glucose (Amersham; $270 \mathrm{Ci} / \mathrm{mol}$ ) added in a final volume of $200 \mu \mathrm{l}$ in a Warburg flask. The above concentrations are those in incubations; incubation mixtures were made up at 1.5 times those concentrations and filter-sterilised. Then 1 vol of bacterial suspension was added to $2 \mathrm{vol}$ of incubation mixture to start incubations. $\mathrm{CO}_{2}$ was absorbed during incubation in $1 \mathrm{M} \mathrm{NaOH}(150 \mu \mathrm{l})$ in the centre well. These are essentially incubation mixtures used in previous studies (Khanolkar and Wheeler, 1983; Wheeler, 1983), except that the radiochemicals were used with no non-radioactive carrier present, so the concentrations in the mixtures were: for hypoxanthine, $1.2 \mu \mathrm{M}$, and glucose, $18.5 \mu \mathrm{M}$.

Suspensions of bacteria were usually added to incubations immediately after harvesting as described above. However, some suspensions were either treated or stored as follows: (a) suspensions of $M$. leprae and $M$. microti $\left(3 \times 10^{9}\right.$ bacteria $\left./ \mathrm{ml}\right)$ were made in PBS $(p \mathrm{H} \mathrm{7.0)}$ containing Tween $800.05 \% \mathrm{v} / \mathrm{v}$ and treated at $25^{\circ} \mathrm{C}$ with $23.5 \mathrm{mM} \mathrm{H}_{2} \mathrm{O}_{2}$ for $90 \mathrm{~min}$ (Sharp et al., 1985), or formaldehyde $4 \% \mathrm{v} / \mathrm{v}$ for $18 \mathrm{~h}$, or hycolin $1 \% \mathrm{v} / \mathrm{v}$ for $18 \mathrm{~h}$. During treatment with $\mathrm{H}_{2} \mathrm{O}_{2}$, the concentration of $\mathrm{H}_{2} \mathrm{O}_{2}$ was monitored; after $45 \mathrm{~min}$, it had fallen from $23.5 \mathrm{mM}$, to $21.6 \mathrm{mM}$ so further $\mathrm{H}_{2} \mathrm{O}_{2}$ was added to restore the concentration to $23.5 \mathrm{~mm}$. After the above treatments, the bacteria were centrifuged and washed three times in buffered Tween 80 before being added to the incubation medium. (b) $M$. leprae, either as a suspension or before isolation (i.e., in infected armadillo tissue) was subjected to a 2.5 MRad dose of $\gamma$-irradiation from the ${ }^{60} \mathrm{Co}$ source at the National Institute for Medical Research, London NW7 1AA. This dose was calculated to leave 1 surviving bacterium in $10^{60}$ (P. Draper and R. J. W. Rees, personal communication). (c) Suspensions of $M$. leprae at three times the density used in incubations were stored at $4^{\circ} \mathrm{C}$ for up to 27 days in either buffered Tween 80, 5 mM MES adjusted to $p \mathrm{H} 6.8$ with $6 \mathrm{M} \mathrm{NaOH}$, or modified Dubos Medium at $p \mathrm{H}$ 6. After storage, the bacteria were washed twice with buffered Tween 80 , suspended in a small volume of buffered Tween 80 , and added to incubation medium at the rate of $100 \mu \mathrm{l}$ /incubation.

Anti-leprosy agents were added, when required, to the incubation media, and $M$. leprae added afterwards. In general, leprosy bacilli were added to incubation media to start incubations. However, when they were preincubated with anti-leprosy agents, the incubation medium was complete except for $\left[\mathrm{G}-{ }^{3} \mathrm{H}\right]$ hypoxanthine, which was added after the pre-incubation period $(24 \mathrm{~h}$ at $34^{\circ} \mathrm{C}$ ) to start incubations.

At the end of the incubation period, $5 \mu \mathrm{l}$ of the 
suspension was spread on to nutrient agar plates to check for contamination. Results from any contaminated incubations were discarded. Incorporation of $\left[\mathrm{G}-{ }^{3} \mathrm{H}\right]$ hypoxanthine was measured by collecting the remaining bacteria from each incubation on a Whatman GFC filter (Whatman Ltd, Maidstone, Kent), then washing each filter twice with $10 \mathrm{ml}$ of buffered Tween 80 and three times with $10 \mathrm{ml}$ of ice-cold trichloroacetic acid $5 \% \mathrm{v} / \mathrm{v}$. Uptake of $\left[\mathrm{U}-{ }^{14} \mathrm{C}\right]$ glucose was measured by collecting bacteria as above and washing through the filters by vacuum. Filters were dried under a lamp, placed in scintillation vials and scintillation fluid was added so that radioactivity was determined on the filters. After experiments with $\left[\mathrm{U}-{ }^{14} \mathrm{C}\right]$ glucose, the $\mathrm{NaOH}$, with absorbed ${ }^{14} \mathrm{CO}_{2}$, was also added to scintillation vials and scintillation fluid added. Bray's Scintillation Fluid (2, 5-diphenyloxazole $4 \mathrm{~g}$, naphthalene $60 \mathrm{~g}$, methanol $100 \mathrm{ml}$, ethanediol $20 \mathrm{ml}$, made up to 11 with dioxan) was used but most water-tolerating scintillation fluids that render glass-fibre filters transparent could be used. Radioactivity was determined by scintillation counting. In presenting the results, background incorporation of hypoxanthine in heat-killed $\left(100^{\circ} \mathrm{C}\right.$ for $\left.15 \mathrm{~min}\right)$ bacteria was subtracted from incorporation in bacteria which were not heatkilled-except where the terms 'live' or 'heat-killed' are specified in the results. Storage at $4^{\circ} \mathrm{C}$, treatments and incubation with anti-leprosy agents did not affect background incorporation.

\section{Tests of statistical significance and minimum inhibitory concentrations (MICs)}

Significance tests were done by the Wilcoxon (RankSum) test (Colquhoun, 1971) on relative activity values for individual incubations, where the mean relative activity in incubations of freshly isolated bacteria without anti-leprosy agents was 100 .

Minimum inhibitory concentrations (MICs) of antileprosy agents are defined for the purpose of this paper as 'the concentration of agent required to give significant $(\mathrm{p}<0.05)$ inhibition of hypoxanthine incorporation and above which significant $(\mathrm{p}<0.05)$ inhibition of hypoxanthine incorporation is always observed'.

\section{Results}

Hypoxanthine incorporation by live and killed $M$. leprae

The mean rate of incorporation of $\left[\mathrm{G}^{-3} \mathrm{H}\right]$ hypoxanthine into material insoluble in cold trichloroacetic acid with four isolates of $M$. leprae from infected tissues (three frozen, one fresh) was $41500 \mathrm{SE} 3800 \mathrm{dpm} / 10^{10} M$. leprae $/ 24 \mathrm{~h}$. There was no marked increase in hypoxanthine incorporation by $M$. leprae isolated from fresh tissue and it was not significantly lower in isolates from the same tissues stored at $-70^{\circ} \mathrm{C}$ for up to 11 months. The mean rate of incorporation was $38400 \mathrm{SE} 9200 \mathrm{dpm} / 10^{10}$ M. leprae $/ 24 \mathrm{~h}$ in five subsequent isolates and $39800 \mathrm{SE} 6000 \mathrm{dpm} / 10^{10}$ $M$. leprae $/ 24 \mathrm{~h}$ in all nine isolates.

It was decided to include $10^{9}-10^{10} \mathrm{M}$. leprae organisms in each incubation after a comparison of incubations with $1.6 \times 10^{9}$ and $3.2 \times 10^{7} \mathrm{M}$. leprae. In incubations with $1.6 \times 10^{9}$ organisms for $24 \mathrm{~h}$, radioactivity incorporated in all incubations with heat-killed bacteria (712 dpm: 6 determinations) was lower than in all incubations with live bacteria (6051 dpm: 14 determinations). In incubations with $3.2 \times 10^{7}$ organisms for 7 days, radioactivity incorporated by the live bacteria $(1161 \mathrm{dpm}$ : 20 determinations) was still significantly higher $(\mathrm{p}<0.05)$ than by heat-killed bacteria (716 dpm: 9 determinations). However, in many individual incubations with heat-killed bacteria, the radioactivity incorporated was higher than in some individual incubations with live bacteria. Thus the rank-sum of the incubations with heat-killed bacteria was 82 (minimum possible rank-sum for $n=9$ is 45 ).

When suspensions of $M$. leprae were treated by incubation in $\mathrm{H}_{2} \mathrm{O}_{2}$, hycolin, or formaldehyde or by $\gamma$-irradiation to kill $>99 \%$ of the organisms, hypoxanthine incorporation was significantly inhibited $(\mathrm{p}<0.05)$ by all treatments, which abolished $67-97 \%$ of the activity depending on the treatment (table I). Similar effects were observed with $M$. microti OV 254 grown on modified Dubos Medium at $p \mathrm{H} \mathrm{7,} \mathrm{showing} \mathrm{that} \mathrm{hypoxanthine} \mathrm{incorporation}$ reflected the viability of suspensions of at least one other mycobacterium grown in culture medium (table I).

Effect on hypoxanthine incorporation of storage of $M$. leprae at $4^{\circ} \mathrm{C}$

When freshly isolated purified leprosy bacilli were stored at $4^{\circ} \mathrm{C}$ as a suspension in Tween 80 $0.05 \%$ buffered with $5 \mathrm{mM}$ MES at $p \mathrm{H} \mathrm{7,} \mathrm{their}$ viability, as judged in the mouse foot-pad, decreased exponentially with time (A. C. R. E. Lowe, personal communication). However, their hypoxanthineincorporating activity increased for the first 15 days of storage, then fell. Only after 27 days was the hypoxanthine-incorporating activity significantly below the activity of freshly isolated bacteria (fig. 1). When Tween 80 was omitted, the effect of storage on hypoxanthine incorporation in $M$. leprae was similar to when Tween 80 was present (fig. 1) showing that it was not Tween 80 that was responsible for the initial increase in the ability of $M$. leprae to incorporate hypoxanthine.

The ATP content of $M$. leprae falls rapidly during storage in buffered Tween 80 at $4^{\circ} \mathrm{C}$ (Nam Lee and Colston, 1985) but considerably less rapidly in 
Table I. Effect on hypoxanthine incorporation of killing without destroying enzymes

\begin{tabular}{|c|c|c|c|c|}
\hline \multirow[b]{2}{*}{ Treatment } & \multicolumn{2}{|c|}{ M. leprae } & \multicolumn{2}{|c|}{ M. microti OV 254} \\
\hline & $\begin{array}{l}\text { Viability after } \\
\text { treatment }(\%)\end{array}$ & $\begin{array}{l}\text { Relative* } \\
\text { activity }\end{array}$ & $\begin{array}{l}\text { Viability after } \\
\text { treatment }(\%)\end{array}$ & $\begin{array}{l}\text { Relative* } \\
\text { activity }\end{array}$ \\
\hline None & $\cdots$ & 100 & 100 & 100 \\
\hline $\begin{array}{l}\gamma \text {-irradiation of suspension ( } 2.5 \mathrm{MRad}): \text { hypoxanthine }+ \\
\text { incubation medium added immediately after irradiation }\end{array}$ & 0 & 33 & 0 & 0 \\
\hline $\begin{array}{l}\gamma \text {-irradiation of tissue }(2.5 \mathrm{MRad}): \text { storage for } 2 \text { months at } \\
-70^{\circ} \mathrm{C} \text { before } \tilde{M} \text {. leprae } \text { was harvested }\end{array}$ & 0 & 3 & $\ldots$ & $\ldots$ \\
\hline $\mathrm{H}_{2} \mathrm{O}_{2}(23.5 \mathrm{mM}), p \mathrm{H} 7,90 \mathrm{~min}$ & $1 \dagger$ & 24 & $\ldots$ & $\ldots$ \\
\hline $\mathrm{H}_{2} \mathrm{O}_{2}(23.5 \mathrm{~mm}), p \mathrm{H} 4.5,90 \mathrm{~min}$ & $\ldots$ & $\cdots$ & 8 & 9 \\
\hline Formaldehyde $4 \%, 18 \mathrm{~h}$ & $\ldots$ & 20 & $<0.01$ & $\ldots$ \\
\hline Hycolin $1 \%, 18 \mathrm{~h}$ & $\ldots$ & 11 & $<0.01$ & $\ldots$ \\
\hline
\end{tabular}

Viability determinations for $M$. microti were done by plating on to Sauton's medium.

*Each figure represents the mean activity relative to the activity (in one experiment) when no treatments were done; 100 represents $26400 \mathrm{dpm} / 10^{10} M$. leprae $/ 24 \mathrm{~h}$ and $59200 \mathrm{dpm} / 10^{10} M$. microti $/ 24 \mathrm{~h}$. Each figure represents $3-5$ determinations.

$\dagger$ from Sharp et al., 1985.

$\ldots=$ Not done

modified Dubos Medium adjusted to $\mathrm{pH} 6$ and without serum albumin (H. S. Heine, personal communication). As the ATP content might reflect the content of intracellular nucleotides in general and such changes might affect hypoxanthine uptake and incorporation, the effect of storing $M$. leprae in modified Dubos Medium, $p \mathrm{H} 6$ at $4^{\circ} \mathrm{C}$ was investigated. In this medium, the ability of the bacteria to incorporate hypoxanthine decreased continuously throughout the period of storage (fig. 1).

\section{Effect of anti-leprosy agents on hypoxanthine incorporation by $M$. leprae}

The anti-leprosy agents dapsone, brodimoprim and clofazamine significantly inhibited hypoxanthine incorporation in $M$. leprae as did the experimental agents SC-SE 60 and $\mathrm{Li} 014$ (fig. 2). However, dapsone was the only agent which produced nearly complete inhibition of hypoxanthine incorporation. MICs for hypoxanthine incorporation were, for dapsone, $10 \mathrm{ng} / \mathrm{ml}$; for clofazamine, $100 \mathrm{ng} / \mathrm{ml}$; for $\mathrm{Li} 014,3 \mu \mathrm{g} / \mathrm{ml}$; for brodimoprim, $10 \mu \mathrm{g} / \mathrm{ml}$ and for SC-SE $60,30 \mu \mathrm{g} /$ $\mathrm{ml}$ (deduced from data in fig. 2).

When $M$. leprae was pre-incubated with antileprosy agents in the incubation medium before hypoxanthine was added, relative incorporation values were as follows: with no agent, 100 (=76 $400 \mathrm{dpm} / 10^{10} M$. leprae $\left./ 24 \mathrm{~h}\right)$; with DDS $3 \mathrm{ng} / \mathrm{ml}, 109$; with DDS $10 \mathrm{ng} / \mathrm{ml}, 63$; with DDS $30 \mathrm{ng} / \mathrm{ml}, 41$; with SC-SE $6010 \mu \mathrm{g} / \mathrm{ml}, 103$; with SC-SE $60100 \mu \mathrm{g} / \mathrm{ml}$, 94; with Li $01410 \mu \mathrm{g} / \mathrm{ml}, 55$; and with $\mathrm{Li} 014100 \mu \mathrm{g} / \mathrm{ml}, 46$. With the exception

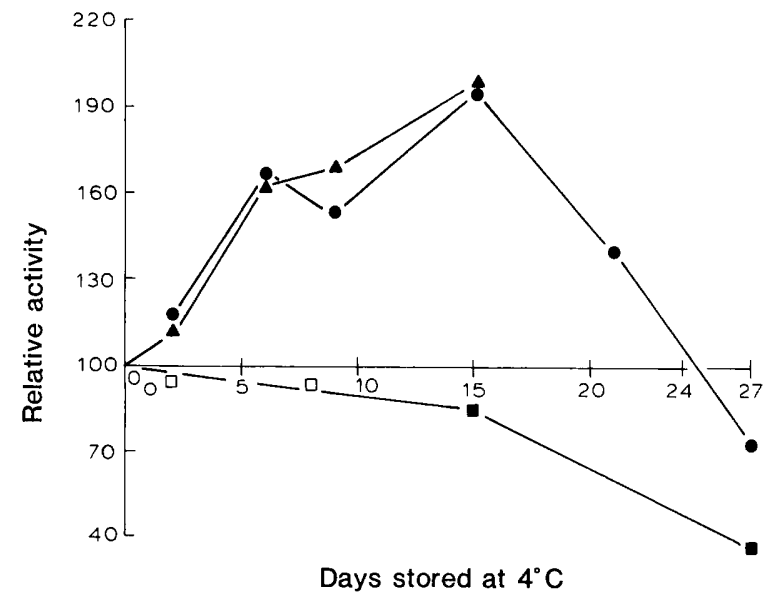

Fig. 1. Effect of storage at $4^{\circ} \mathrm{C}$ on hypoxanthine incorporation in $M$. leprae: $\bigcirc-$ storage in $5 \mathrm{mM}-\mathrm{MES}, p \mathrm{H} \mathrm{6.8+Tween} 80$ $0.05 \% ; \Delta-\mathbf{A}$ storage in $5 \mathrm{mM}-\mathrm{MES}, p \mathrm{H} 6.8 ; \square-\square$ storage in modified Dubos Medium, $p \mathrm{H} 6$ - no serum albumin but Tween $800.05 \%$ was included. Significant difference $(p<0.05)$ of incorporation in stored $M$. leprae from incorporation in freshly isolated $M$. leprae is shown by filled symbols. Each symbol represents the mean activity relative to incubations with freshly isolated $M$. leprae. 100 represents $39800 \mathrm{dpm} / 10^{10} M$. leprae/ $24 \mathrm{~h}$.

of incubations with SC-SE $60100 \mu \mathrm{g} / \mathrm{ml}$ these values were very similar to those in fig. 2 . When penicillin and the pyrimidines were omitted from the incubation medium, relative incorporation values were as follows: with no agent, 100 (=14500 dpm $/ 10^{10} M$. leprae $/ 24 \mathrm{~h}$ ); with DDS $1 \mathrm{ng} / \mathrm{ml}, 81$; with DDS $3 \mathrm{ng} / \mathrm{ml}$, 66; with DDS $10 \mathrm{ng} / \mathrm{ml}, 41$; with DDS $30 \mathrm{ng} / \mathrm{ml}$, 41; with DDS 


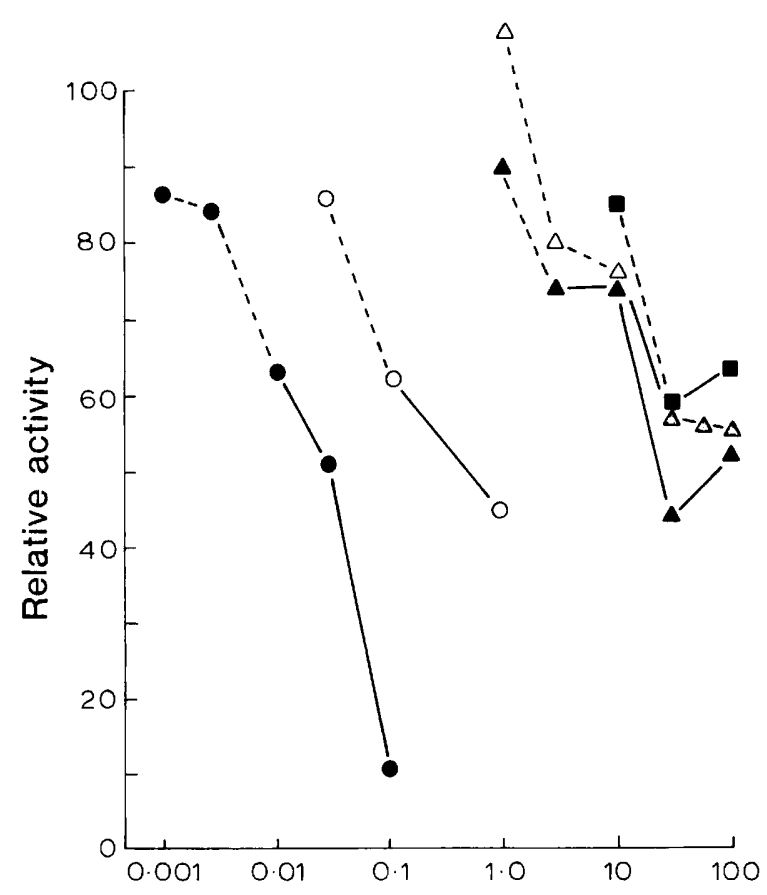

Concentration of agent $(\mu \mathrm{g} / \mathrm{ml})$

Fig. 2. Effect of anti-leprosy agents on hypoxanthine incorporation in dapsone-sensitive $M$. leprae: - dapsone; $\bigcirc-\mathrm{O}$

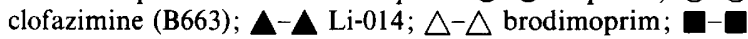
SC-SE 60. Significant inhibition (taken as $p<0.05$ but in fact $p$ always $<0.01$ ) of hypoxanthine incorporation occurred at concentrations of agents shown by symbols connected by unbroken lines. Each symbol represents the mean activity relative to activity with no additions, and represents 3 or 4 determinations except at the MIC, where 6-10 determinations were done; 100 represents $39800 \mathrm{dpm} / 10^{10} \mathrm{M}$. leprae $/ 24 \mathrm{~h}$.
$100 \mathrm{ng} / \mathrm{ml}, 21$; and with Li $014100 \mu \mathrm{g} / \mathrm{ml}, 50$. These relative values were similar to those shown in fig. 2 , for which the complete incubation medium was used. Thus penicillin and either dapsone or Li 014 were not acting synergically, and penicillin can be used in the incubation medium.

Combinations of dapsone and agents acting on dihydrofolate reductase acted synergically by inhibiting hypoxanthine incorporation in $M$. leprae significantly at concentrations which, when used alone, did not have a significant effect on hypoxanthine incorporation (table II). In four out of five of these combinations, the combined effect was greater than the sum of the inhibition caused by each agent alone. However, if a more stringent test for synergic action - whether the inhibition by any combination of agents significantly inhibits the activity of hypoxanthine incorporation in the presence of each agent alone-was applied, synergy was observed only between dapsone $3 \mathrm{ng} / \mathrm{ml}$ and brodimoprim $3 \mu \mathrm{g} / \mathrm{ml}$ (table II).

Synergy between dapsone and brodimoprim was more easily detected in dapsone-resistant $M$. leprae which were harvested from Armadillo 603. Armadillo 603 was inoculated with $M$. leprae from two patients in Madras. The bacteria were resistant to dapsone in the plasma of mice at up to $1 \mu \mathrm{g} / \mathrm{ml}$ (Rees, personal communication). 603 was part of the NIMR bank of infected armadillos.

In dapsone-resistant organisms, hypoxanthine incorporation was not significantly inhibited by dapsone $100 \mathrm{ng} / \mathrm{ml}$ (table III) although curiously dapsone $30 \mathrm{ng} / \mathrm{ml}$ did cause significant inhibition. However, if hypoxanthine incorporation in control incubations (i.e., without dapsone) was compared with activity in (a) any concentration of dapsone or

Table II. Effect of combinations of anti-leprosy agents on hypoxanthine-incorporation in dapsone-sensitive $M$. leprae

\begin{tabular}{lccccc}
\hline & \multicolumn{5}{c}{ Relative activity of agents (a) (below) with agents (b) } \\
\cline { 2 - 6 } Agent (b) & None & $\begin{array}{c}\text { brodimoprim } \\
1 \mu \mathrm{g} / \mathrm{ml}\end{array}$ & $\begin{array}{c}\text { brodimoprim } \\
3 \mu \mathrm{g} / \mathrm{ml}\end{array}$ & $\begin{array}{c}\text { brodimoprim } \\
30 \mu \mathrm{g} / \mathrm{ml}\end{array}$ & $\begin{array}{c}\text { SC-SE } 60 \\
10 \mu \mathrm{g} / \mathrm{ml}\end{array}$ \\
\hline None & $100(23)$ & 107 & $80(7)$ & $57 \ddagger$ & $85(10)$ \\
$1 \mathrm{ng} / \mathrm{ml}$ dapsone & 86 & $70 \dagger$ & $69 \dagger$ & $53 \ddagger$ & 95 \\
$3 \mathrm{ng} / \mathrm{ml}$ dapsone & $84(8)$ & $67 \ddagger$ & $50^{*} \ddagger$ & $\ldots$ & $64 \ddagger$ \\
$10 \mu \mathrm{g} / \mathrm{ml}$ SC-SE 60 & $85(10)$ & $\ldots$ & 80 & $\ldots$ & $\ldots$ \\
\hline
\end{tabular}

* Significant inhibition $(p<0.05)$ of hypoxanthine incorporation by combinations of agents, when compared with inhibition by agent (a) or (b) alone.

Inhibition of hypoxanthine incorporation by combination of agents was significant $(\uparrow ; \mathrm{p}<0 \cdot 05$, or $\ddagger ; \mathrm{p}<$ $0.01)$ compared with hypoxanthine incorporation in the absence of any anti-leprosy agents.

Each figure represents the mean activity relative to activity with no additions $\left(39800 \mathrm{dpm} / 10^{10} M\right.$. leprae) $24 \mathrm{~h}$ ), and represents 3-6 determinations except where the number of determinations is shown in brackets. ... = Not done. 
Table III. Effect of combinations of dapsone and agents acting on dihydrofolate reductase on hypoxanthine incorporation in dapsone-resistant $M$. leprae

\begin{tabular}{lccccc}
\hline & \multicolumn{5}{c}{ Relative activity of anti-dihydrofolate reductase agents (below) with } \\
dapsone
\end{tabular}

Each figure represents the mean activity relative to activity with no additions $\left(50360 \mathrm{dpm} / 10^{10} M\right.$. leprae $/ 24 \mathrm{~h}$ ). In column 1 (no anti-dihydrofolate reductase agents) each figure represents 4 determinations; all other figures represent $2-3$ determinations.

* Significant inhibition; $p<0.05$. The effect on hypoxanthine incorporation of each antidihydrofolate reductase agent was compared with hypoxanthine incorporation in all incubations without anti-dihydrofolate inhibitors.

$\ldots=$ Not done.

(b) dapsone $30-100 \mathrm{ng} / \mathrm{ml}$ (by pooling the results used in table III) no significant inhibition of activity by dapsone could be shown. This suggests that the inhibition with dapsone $30 \mathrm{ng} / \mathrm{ml}$ was an anomolous result and perhaps it could be considered to be the one 'false positive' in these results. However, when brodimoprim or SC-SE 60 at concentrations which did not by themselves inhibit hypoxanthine incorporation were added to suspensions of dapsoneresistant $M$. leprae together with dapsone $0-100 \mathrm{ng} /$ $\mathrm{ml}$, inhibition of hypoxanthine incorporation was clearly observed. Indeed, with a combination of brodimoprim $3 \mu \mathrm{g} / \mathrm{ml}$ and dapsone 30 or $100 \mathrm{ng} /$ $\mathrm{ml}$, complete inhibition of hypoxanthine incorporation was nearly achieved (table III), an effect otherwise only observed with dapsone-sensitive $M$. leprae plus dapsone $100 \mathrm{ng} / \mathrm{ml}$.

\section{Effect of anti-leprosy agents and hypoxanthine on evolution of $\mathrm{CO}_{2}$ from glucose}

The mean rate of evolution of ${ }^{14} \mathrm{CO}_{2}$ from [U$\left.{ }^{14} \mathrm{C}\right]$ glucose over $20 \mathrm{~h}$ was $6290 \mathrm{SE} 506 \mathrm{dpm} / 10^{10}$
M. leprae (17 determinations). Radioactivity taken up into the washed bacteria was $34900 \mathrm{dpm} / 10^{10}$ $M$. leprae after incubation for $20 \mathrm{~h}$.

SC-SE 60 and dapsone significantly inhibited evolution of $\mathrm{CO}_{2}$ from glucose (table IV) at similar concentrations to those at which they inhibited hypoxanthine incorporation (fig. 2). These observations were exploited to screen for any possible effect of hypoxanthine on $M$. leprae by using $\mathrm{CO}_{2}$ evolution from glucose as an 'alternative drugscreening' method. Hypoxanthine on its own had no effect and did not potentiate the effect of SCSE 60 or dapsone (table IV). In these experiments hypoxanthine was used at $3.3 \mu \mathrm{M}$ (the concentration in incubations when $1 \mu \mathrm{Ci}$ of hypoxanthine at $1 \mathrm{Ci} /$ mmol was used in studies of hypoxanthine incorporation) or $80 \mu \mathrm{M}$, at which concentration it potentiates the effect of trimethoprim (another benzylpyrimidine) on $E$. coli (Bruce et al., 1984). Similar effects of anti-leprosy agents and hypoxanthine were observed on uptake of glucose (results not presented).

Table IV. Effect of anti-leprosy agents and hypoxanthine on production of ${ }^{14} \mathrm{CO}_{2}$ from $\left[\mathrm{U}-{ }^{14} \mathrm{C}\right]$ glucose by $M$. leprae

\begin{tabular}{lrccccc}
\hline & \multicolumn{5}{c}{ Relative activity of anti-leprosy agent (below) with hypoxanthine } \\
\cline { 2 - 7 } Hypoxanthine added & None & $\begin{array}{c}\text { dapsone } \\
1 \mathrm{ng} / \mathrm{ml}\end{array}$ & $\begin{array}{c}\text { dapsone } \\
50 \mathrm{ng} / \mathrm{ml}\end{array}$ & $\begin{array}{c}\text { dapsone } \\
50 \mathrm{ng} / \mathrm{ml}\end{array}$ & $\begin{array}{c}\text { SC-SE 60 } \\
10 \mu \mathrm{g} / \mathrm{ml}\end{array}$ & $\begin{array}{c}\text { SC-SE 60 } \\
100 \mu \mathrm{g} / \mathrm{ml}\end{array}$ \\
\hline None & 100 & 110 & $57^{*}$ & $54^{*}$ & $73^{*}$ & $31^{*}$ \\
$3 \cdot 3 \mu \mathrm{M}$ & 97 & 90 & $\ldots$ & $55^{*}$ & 111 & $\ldots$ \\
$80 \mu \mathrm{M}$ & 111 & 78 & $55^{*}$ & $59^{*}$ & 105 & $34^{*}$ \\
\hline
\end{tabular}

Each figure represents the mean activity relative to activity with no additions. Except for incubations with no additions (17 determinations; mean $=6290 \mathrm{dpm} / 10^{10} \mathrm{M}$. leprae $/ 24 \mathrm{~h}$ ) each figure represents $3-4$ determinations.

* Significant inhibition; $\mathrm{p}<0.05$

$\ldots=$ Not done. 


\section{Discussion}

During studies on purine metabolism in $M$. leprae, it was shown that three anti-leprosy agents inhibited the incorporation of hypoxanthine (Khanolkar and Wheeler, 1983). Those observations are extended here by showing statistically significant inhibition of hypoxanthine incorporation by five further anti-leprosy agents which have different primary effects. These included four agents with targets in folate metabolism: dapsone, which inhibits dihydropteroate synthetase (Kulkarni and Seydel, 1983) and three benzylpyrimidines, which inhibit dihydrofolate reductase (Seydel et al., 1983; Seydel and Kraus, personal communication). The fifth agent, clofazamine, probably works by intercalating nucleic acid molecules and consequently blocking transcription. Thus only one agent, clofazamine, has a direct effect on the pathway for hypoxanthine incorporation-uptake, conversion to nucleotides, and assembly of nucleotides into nucleic acids - which has been shown to exist in $M$. leprae (Khanolkar and Wheeler, 1983). The established agents, dapsone (Ellard, 1974) and clofazamine (Shepard, 1960) significantly inhibited hypoxanthine incorporation at concentrations at which they exert their pharmacological effects. The benzylpyramides, which are experimental agents, significantly inhibited hypoxanthine incorporation at or near concentrations that inhibited dihydrofolate reductase in extracts of $M$. leprae (Seydel and Kraus; personal communication) or in killed suspensions of M. lufu (Seydel et al., 1983), the latter being the organism of choice as a model for folate metabolism in $M$. leprae (Kulkarni and Seydel, 1983; Seydel et al., 1983). In these experiments, maximum inhibition of hypoxanthine incorporation was only $50-60 \%$ (table II) for agents other than dapsone. This degree of inhibition may not be exceeded as many of the agents came out of solution at concentrations higher than those tested. An important observation was that dapsone did not inhibit hypoxanthine incorporation in dapsoneresistant $M$. leprae, showing that when an agent had no chemotherapeutic effect it did not affect hypoxanthine incorporation either. It appeared possible to detect synergy between dapsone and inhibitors of dihydrofolate reductase, although the synergy was only obvious when high concentrations of dapsone were used against dapsone-resistant $M$. leprae. Synergy has been shown with these agents in similar combinations against $M$. lufu, including dapsone-resistant strains (Seydel et al., 1983; Seydel and Kraus, personal communication).

Two agents in the incubation mixtures routinely used could possibly have potentiated the effect of some of anti-leprosy agents tested. In particular, hypoxanthine itself potentiates the effect of a benzylpyrimidine, trimethoprim, in $E$. coli (Bruce et al., 1984) so a similar effect might have been observed in $M$. leprae. However, no potentiating effects of either hypoxanthine or penicillin were observed in these studies. To seek any effect of hypoxanthine on $M$. leprae an alternative screening method, relying on ${ }^{14} \mathrm{CO}_{2}$ evolution from $\left[{ }^{14} \mathrm{C}\right]$ glucose was devised. This activity, which was inhibited by dapsone and SC-SE 60, may itself be suitable for screening anti-leprosy agents, although it is hypoxanthine incorporation which, as a result of these findings, is recommended as a method for screening.

Hypoxanthine incorporation in suspensions of $M$. leprae was not directly related to the viability of the bacteria as judged by infectivity for the mouse foot-pad, but, generally, suspensions with a greater proportion of viable cells had higher activities of hypoxanthine incorporation. However, during storage of leprosy bacilli at either $4^{\circ} \mathrm{C}$ or $34^{\circ} \mathrm{C}$ (i.e., the latter in experiments requiring pre-incubation for $24 \mathrm{~h}$ ) hypoxanthine incorporation increased initially before falling. Concomitantly, an exponential decrease in viability occurred. Thus the initial increase in $\left[\mathrm{G}^{-3} \mathrm{H}\right]$ hypoxanthine incorporation may have been a result of intracellular nucleotides becoming depleted during storage so that a greater proportion of the purine nucleotide pool was derived from $\left[\mathrm{G}^{-}{ }^{3} \mathrm{H}\right]$ hypoxanthine in stored $M$. leprae than in fresh $M$. leprae. This suggestion is supported by the observation that the initial increase in hypoxanthine incorporation on storage occurred when $M$. leprae organisms were kept in a medium in which ATP (i.e., the one nucleotide that has been measured in $M$. leprae) content was rapidly depleted. During an earlier study of thymidine incorporation into $M$. leprae, more radioactivity was incorporated into leprosy bacilli kept for 9 days in an alleged culture medium (M-Y medium; Murohashi and Yoshida, 1975) than into freshly isolated leprosy bacilli suspended in the same medium (Ambrose et al., 1978). At that time the higher incorporation at 9 days was explained by suggesting that ' $M-Y$ ' medium, might be promoting nucleic acid synthesis or even growth. Subsequently, 'M-Y' medium was dismissed as a culture medium for $M$. leprae (Nakamura et al., 1982). Thus the observations of Ambrose et al. (1978) may also reflect depletion of nucleotides during storage in ' $\mathrm{M}$-Y' medium. These results show how important it is to test a potential method for determining viability with organisms which have been killed 
without destroying the activity being measured. For an activity to be related to viability, it must be shown to decrease rapidly as the organism loses its metabolic competence after killing.

Thus, the usefulness of hypoxanthine incorporation seems to be greatest as a method for preliminary screening of new potential anti-leprosy agents. Those agents that inhibit hypoxanthine incorporation could then be tested in experimental animals and, eventually, patients. Clear-cut results were obtained easily and quickly with $\sim 10^{9} \mathrm{M}$. leprae/ incubation, and at this rate a heavily infected armadillo liver could supply enough bacteria for 1000 incubations. More replicates would have to be done with $\sim 10^{7} M$. leprae/incubation in 6 day incubations, but with only about $50 \%$ inhibition by

\section{REFERENCES}

Ambrose E J, Khanolkar S R, Chulawalla R G 1978 A rapid test for bacillary resistance to dapsone. Leprosy in India 50: 131-143.

Bruce I, Hardy J, Stacey K A 1984 Potentiation by purines of the growth inhibitory effects of sulphonamides on Escherichia coli $\mathrm{K} 12$ and the location of the gene which mediates this effect. Journal of General Microbiology 130: 2489-2495.

Cartel J L, Millan J, Guelpa-Lauras C C, Grosset J H 1983 Hepatitis in leprosy patients treated by a daily combination of dapsone, rifampin, and a thioamide. International Journal of Leprosy 51 : $461-465$.

Colquhoun D 1971 Numerical and rank measurements. Lectures on Biostatistics, Clarendon Press, Oxford: pp 137-151.

Colston M J, Hilston G R F, Banerjee D K 1978 The "proportional bactericidal test": a method for assessing bactericidal activity of drugs against Mycobacterium leprae in mice. Leprosy Review 49:7-15.

Ellard G A 1974 Growing points in leprosy research. 4. Recent advances in the chemotherapy of leprosy. Leprosy Review 45: $31-40$.

Guelpa-Lauras C C, Grosset J H, Constant-Desportes M, Brucker G 1984 Nine cases of rifampin-resistant leprosy. International Journal of Leprosy 52: 101-102.

Khanolkar S R, Wheeler P R 1983 Purine metabolism in Mycobacterium leprae grown in armadillo liver. FEMS Microbiology Letters 20: 273-278.

Kulkarni V M, Seydel J K 1983 Inhibitory activity and mode of action of diaminodiphenylsulfone in cell-free folate synthesizing systems prepared from Mycobacterium lufu and Mycobacterium leprae: a comparison. Chemotherapy 29: 5867.

Kvach J T, Munguia G, Strand S H, 1984 Staining tissue derived Mycobacterium leprae with fluorescein diacetate and ethidium bromide. International Journal of Leprosy 52: 176-182.

Mankar M V, Jagannathan R, Mahadevan P R 1984 In vitro drug screening system using membrane alteration in macrophages by Mycobacterium leprae. Journal of Biosciences 6: 709-716.

Mittal A, Sathish M, Seshadri P S, Nath I 1983 Rapid, radiolabeled-microculture method that uses macrophages for in vitro evaluation of Mycobacterium leprae viability and drug susceptibility. Journal of Clinical Microbiology 17: 704-707.

Murohashi T, Yoshida K 1975 Attempts to culture Mycobacterium leprae in culture media. Acta Leprologica 58: 5-21. some agents, clear cut results would be more difficult to obtain. Whether or not the method is suitable for evaluating drug resistance in biopsies from patients needs further evaluation, although dapsone resistance could easily be detected. Perhaps the greatest advantage in measuring hypoxanthine incorporation in $M$. leprae is that it is rapid relative to thymidine incorporation (Khanolkar and Wheeler, 1983) and can readily be measured by a fairly simple technique with $M$. leprae suspended in an incubation medium.

I thank C. Ratledge for helpful advice. Armadillos were maintained with funds from LEPRA (British Leprosy Relief Association) or were obtained from the WHO (IMMLEP) armadillo bank. This work was supported by MRC grant $9832233 / \mathrm{T}$.

Nair I, Mahadevan P R 1984 An in vitro test using cholesterol metabolism of macrophages to determine drug sensitivity and resistance of Mycobacterium leprae. Journal of Biosciences 6 : 221-231.

Nakamura $\mathrm{M}$ et al. 1982 Failure to validate the growth of Mycobacterium leprae on M-Y $14 \mathrm{~b}$ agar medium. International Journal of Leprosy 50: 480-487.

Nam Lee Y, Colston M J 1985 Measurement of ATP generation and decay in Mycobacterium leprae in vitro. Journal of General Microbiology 131 : 3331-3337.

Nath I, Prasad H K, Sathish M, Sreevatsa, Desikan K V, Seshadri P S, Iyer C G S 1982 Rapid radiolabeled macrophage culture method for detection of dapsoneresistant Mycobacterium leprae. Antimicrobial Agents and Chemotherapy 21 : 26-32.

Pattyn S R et al. 1984 Hepatoxicity of the combination of rifampin-ethionamide in the treatment of multibacillary leprosy. International Journal of Leprosy 52: 1-6.

Seydel J K, Wempe E G, Rosenfeld M 1983 Bacterial growth kinetics of Escherichia coli and mycobacteria in the presence of brodimoprim and metioprim alone and in combination with sulfamerazine and dapsone. Chemotherapy 29 : 249-261.

Sharp A K, Colston M J, Banerjee D K 1985 Susceptibility of Mycobacterium leprae to the bactericidal activity of mouse peritoneal macrophages and to hydrogen peroxide. Journal of Medical Microbiology 19: 77-84.

Shepard C C 1960 The experimental disease that follows the injection of human leprosy bacilli into footpads of mice. Journal of Experimental Medicine 112: 445-453.

Warndorff-van Diepen T 1982 Clofazimine-resistant leprosya case report. International Journal of Leprosy 50: 139-142.

Wheeler P R 1983 Catabolic pathways for glucose, glycerol and 6-phosphogluconate in Mycobacterium leprae grown in armadillo tissues. Journal of General Microbiology 129: 1481-1495.

World Health Organization 1980 UNDP/World Bank/WHO Special programme for research and training in tropical diseases. Report of the fifth meeting of the scientific working group on the immunology of leprosy (IMMLEP). TDR/IMMLEP-SWG(5)/80-3, Annex 4 World Health Organization, Geneva p. 23.

World Health Organization 1985 UNDP/World Bank/WHO Special programme for research and training in tropical diseases. Tropical disease research, seventh programme report (1 January 1983-31 December 1984). Leprosy, Chapter 8. World Health Organization, Geneva. 